\title{
User satisfaction with commuter walk-in centres
}

\author{
Joanne Coster, Alicia O'Cathain, Jon Nicholl and Chris Salisbury
}

\begin{abstract}
Pilot commuter walk-in centres have been located close to national rail stations in major English cities, provided by private healthcare companies for the NHS, and offering access to doctors and nurses. This study used a survey to evaluate user satisfaction levels with this new service. Thirty-three per cent (1828/5574) of users completed a questionnaire. Centres demonstrated high levels of user satisfaction $(69 \%$ 'very satisfied', $95 \%$ confidence interval $=58 \%$ to $79 \%)$ overall, but satisfaction was lower for some aspects of care such as waiting times.
\end{abstract}

Keywords

evaluation studies; health policy; primary health care; patient satisfaction.
J Coster, BA, MSc, research associate; A O'Cathain, $B S c, M A$, $M S c, C S t a t, P h D$, senior research fellow; J Nicholl, BA, MSc, $D S c, C S t a t$, professor of health services research, director MCRU Policy Research Programme, deputy dean, Medical Care Research Unit, School of Health and Related Research (ScHARR), University of Sheffield, Sheffield. C Salisbury, $M S c, M D, F R C G P$, professor of primary health care, Academic Unit of Primary Health Care, University of Bristol, Bristol.

Address for correspondence

Joanne Coster, Medical Care Research Unit, School of Health and Related Research, University of Sheffield, Sheffield S1 4DA. E-mail: j.e.coster@sheffield.ac.uk

Submitted: 12 March 2009; Editor's response: 7 August 2009; final acceptance: 8 September 2009.

@British Journal of General Practice

This is the full-length article of an abridged version published in print. Cite this article as: $\mathrm{Br} J$ Gen Pract 2009; 10.3399/bjgp09X473169.

\section{INTRODUCTION}

There are currently over 80 walk-in centres in England, located in a variety of settings, most of which offer a nurse-led service. A national evaluation of 40 walk-in centres found that $80 \%$ of users were 'very satisfied' with the service received. ${ }^{1}$ In 2004 the government announced a pilot of seven walk-in centres specifically aimed at people travelling to work by train. These commuter walk-in centres have different aims, and client groups who may have different experiences and satisfaction. In particular, short waiting times may be more important to commuters. As part of a wider evaluation of commuter walk-in centres, reported in an accompanying paper, ${ }^{2}$ satisfaction levels with this new service were measured.

\section{METHOD}

A survey was undertaken to determine how the centres were used and satisfaction with different aspects of care. A user questionnaire was developed, based on one used in the evaluation of general walk-in centres and interviews of users of the new service. ${ }^{1}$ The questionnaire had two parts: the first part, for completion before the consultation, covered reasons for using the walk-in centre, commuting status, and sociodemographic details; the second part, for completion after the consultation, covered waiting time, treatment, referral, and satisfaction. The intention was to ask 600 users in each centre to complete a questionnaire, totalling 3600. Six 'questionnaire days' were selected, when reception staff would hand a questionnaire to all attendees that day. On these days reception staff were asked to give every user an information sheet, questionnaire, and replypaid envelope. Responders could choose to return the completed questionnaire to a box in the reception or post it back to the research team in a reply-paid envelope. No reminders were sent to nonresponders. In practice, there were between 10 and 14 'questionnaire days' in each centre, mainly due to lower than expected numbers using the service. ${ }^{2}$

Responses were entered into SPSS (version 14) for analysis. Descriptive statistics were calculated for all survey questions, and comparisons made between individual centres. Differences between centres were 
tested using $\chi^{2}$ for proportions. Clustering by centre was taken into account when calculating 95\% confidence intervals (Cls) for key estimates, by using the 'regress' command with the 'cluster' option in STATA (version 9.2).

\section{RESULTS}

\section{Response rate}

Routine data from the centres on numbers of users was not available due to commercial sensitivity. Therefore, response rates were calculated based on reports by the centre staff of numbers attending; it was estimated there were 5574 users of the service on the 'questionnaire days'. Of these, 3160 (57\%) were given, and accepted, a questionnaire. A total of $1828 / 3160$ questionnaires were completed, giving a response rate of $58 \%$. The response rate varied between centres and two had a response rate of over $70 \%$. Overall, only $33 \%$ of users completed a questionnaire. Item-response rates reduced for later items on the questionnaire because some responders did not complete the whole questionnaire. Service characteristics and users are described in the accompanying paper. $^{2}$

\section{Reasons for using the commuter walk-in centres}

The questionnaire asked for the main reasons for attending the service that day (Figure 1). The two most frequent reasons were convenience of the service and that it was quicker to get an appointment than in general practice. Only $12 \%(225 / 1815)$ of survey responders reported that they used it because they travelled to work, whereas $40 \%$ $(726 / 1815)$ used it because they worked. If the service had not been available, 54\% (918/1703) of users reported they would have visited their general practice and $11 \%(196 / 1703)$ an emergency department, while $15 \%$ (258/1703) would have looked after the problem themselves.

\section{Experience}

Most users $(80 \%, 1203 / 1500)$ reported that they were seen within 30 minutes; $47 \%(655 / 1390)$ of users

\section{How this fits in}

Walk-in centres are part of primary care provision in England. Centres specifically for commuters were piloted. User were satisfied overall with care but were less satisfied with waiting times.

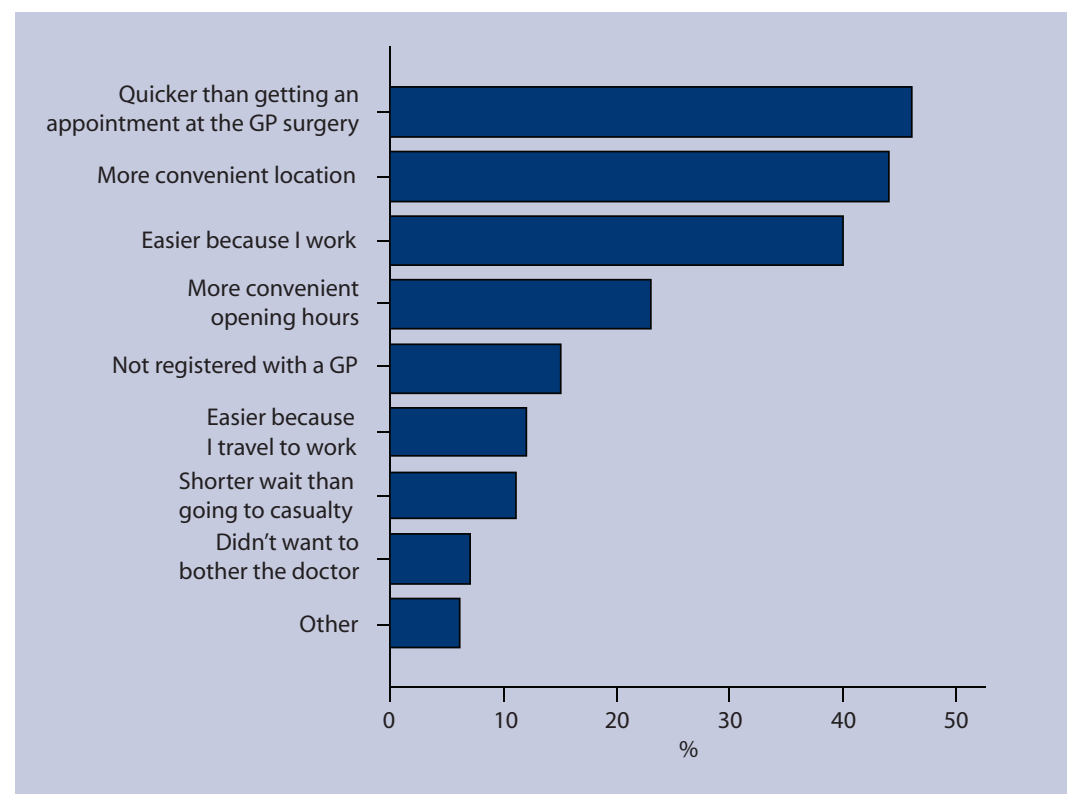

reported being treated by a doctor, or by both a doctor and a nurse. Most users $(77 \%, 1174 / 1524)$ reported receiving advice and information about their health problems, 34\% (515/1524) reported obtaining a Figure 1. Main reasons for choosing commuter walk-in centre rather than elsewhere $(n=1815)$.

Table 1. User satisfaction levels with different aspects of care $(n=1587)$.

\begin{tabular}{lccccc} 
& $\begin{array}{c}\text { Very } \\
\text { satisfied, } \%\end{array}$ & $\begin{array}{c}\text { Fairly } \\
\text { satisfied, } \%\end{array}$ & Uncertain, \% & $\begin{array}{c}\text { Not very } \\
\text { satisfied, \% }\end{array}$ & $\begin{array}{c}\text { Not satisfied } \\
\text { at all, \% }\end{array}$ \\
\hline Receptionist attitude & 71 & 26 & 2 & 1 & $<1$ \\
\hline Time waited & 60 & 29 & 6 & 4 & 1 \\
\hline Nurse/doctor attitude & 78 & 17 & 2 & 2 & $<1$ \\
\hline Explanation given & 70 & 21 & 6 & 2 & $<1$ \\
\hline Treatment or advice & 67 & 24 & 6 & 2 & 1 \\
\hline Overall satisfaction & 69 & 25 & 4 & 1 & 1 \\
\hline
\end{tabular}


Table 2. Treatment received at the commuter walk-in centres.

\begin{tabular}{|c|c|c|c|c|c|c|c|}
\hline & \multicolumn{3}{|c|}{ In London, \% } & \multicolumn{3}{|c|}{ Out of London, \% } & \multirow[b]{2}{*}{ Total, \% } \\
\hline & A & B & C & $\mathrm{D}$ & $E$ & $\mathrm{~F}$ & \\
\hline \multicolumn{8}{|l|}{ Professional seen } \\
\hline Doctor & 28 & 6 & 24 & 11 & 45 & 49 & 28 \\
\hline Nurse & 64 & 91 & 39 & 47 & 40 & 42 & 53 \\
\hline Doctor and nurse & 8 & 3 & 37 & 42 & 15 & 8 & 19 \\
\hline$n=100 \%$ & 237 & 216 & 273 & 161 & 345 & 158 & 1390 \\
\hline \multicolumn{8}{|l|}{ Outcome } \\
\hline Prescription & 35 & 28 & 45 & 35 & 24 & 38 & 34 \\
\hline Medication & 7 & 4 & 10 & 7 & 4 & 5 & 6 \\
\hline Treatment, not medication & 8 & 7 & 19 & 10 & 9 & 7 & 10 \\
\hline Referred to GP & 13 & 19 & 5 & 8 & 9 & 10 & 10 \\
\hline Referred to emergency department/hospital & 8 & 8 & 2 & 3 & 3 & 5 & 5 \\
\hline Asked to return to centre & 5 & $<1$ & 3 & 8 & 4 & 2 & 4 \\
\hline Other (including advice) & 24 & 34 & 16 & 29 & 47 & 33 & 31 \\
\hline$n=100 \%$ & 254 & 237 & 296 & 193 & 359 & 185 & 1524 \\
\hline
\end{tabular}

Table 3. Percentage receiving definitive care at commuter walk-in centre.

\begin{tabular}{|c|c|c|c|c|c|c|c|}
\hline & \multicolumn{3}{|c|}{ In London, \% } & \multicolumn{3}{|c|}{ Out of London, \% } & \multirow[b]{2}{*}{ Total, \% } \\
\hline & A & B & C & D & E & $\mathrm{F}$ & \\
\hline \multicolumn{8}{|l|}{ Centre dealt with the problem } \\
\hline Totally & 65 & 50 & 65 & 75 & 56 & 69 & 62 \\
\hline Partly & 30 & 42 & 28 & 23 & 36 & 28 & 32 \\
\hline No & 5 & 8 & 7 & 2 & 8 & 3 & 6 \\
\hline$n=100 \%$ & 250 & 238 & 297 & 196 & 362 & 182 & 1525 \\
\hline \multicolumn{8}{|l|}{ Intention: } \\
\hline Visit GP & 22 & 35 & 23 & 19 & 24 & 26 & 25 \\
\hline Go to emergency department/hospital & 11 & 8 & 4 & 4 & 3 & 6 & 5 \\
\hline Self-care & 48 & 42 & 51 & 56 & 53 & 49 & 50 \\
\hline Other & 19 & 15 & 22 & 21 & 20 & 19 & 20 \\
\hline$n=100 \%$ & 242 & 229 & 289 & 184 & 351 & 179 & 1474 \\
\hline
\end{tabular}

with different aspects of care, with responders being least satisfied with the time they waited to see the doctor or nurse, and most satisfied with the attitude of the nurse or doctor treating them.

\section{Variation between centres}

There was variation between individual centres in relation to the type of health professional seen by patients $(P=0.001)$, waiting times $(P=0.001)$, and satisfaction with waiting times $(P=0.001)$. Centre ' $\mathrm{B}$ ' in particular was different from the other centres, in terms of both service offered and satisfaction. This centre had a very low rate of reported doctor use (9\%, 20/216) compared with the other centres $(54 \%$, $635 / 1174)$, and also referred more patients to their GP $(19 \%, 44 / 237)$ than the other centres $(9 \%$, 115/1284) (Table 2). Fewer patients using centre 'B' felt that their problem had been totally dealt with (Table 3). Twenty-four per cent (56/233) of users in centre ' $\mathrm{B}$ ' reported waiting more than 40 minutes, compared to $7 \%$ of all other users (92/1267) (Table $4)$, and $15 \%(37 / 241)$ of users in centre 'B' reported dissatisfaction with the time they waited, compared to $4 \%(50 / 1304)$ dissatisfied for all other centres. Centre 'B' also performed less well than the other centres on most aspects of satisfaction (Table 5), and only $51 \%$ of users of centre 'B' (123/239) stated they would definitely return to use the centre again, compared with $69 \%(897 / 1298)$ in other centres.

\section{DISCUSSION}

\section{Summary of main findings}

People used commuter walk-in centres because they were convenient and it was quicker to get an appointment than at a GP surgery. Users appeared satisfied with the centres overall, but were least satisfied with waiting times. Not all centres functioned in the same way, with one centre appearing to have lower satisfaction levels than the others.

\section{Strengths and limitations of the study}

The exact number of people using the service was unavailable due to lack of access to routine data. Sampling bias may have been introduced, as some 
Table 4. Reported waiting time and satisfaction with waiting times.

\begin{tabular}{|c|c|c|c|c|c|c|c|}
\hline & \multicolumn{3}{|c|}{ In London, \% } & \multicolumn{3}{|c|}{ Out of London, \% } & \multirow[b]{2}{*}{ Total, \% } \\
\hline & A & B & $\mathrm{C}$ & $\mathrm{D}$ & $E$ & $\mathrm{~F}$ & \\
\hline \multicolumn{8}{|c|}{ Waiting times, minutes } \\
\hline$<10$ & 72 & 16 & 13 & 49 & 58 & 46 & 43 \\
\hline $11-30$ & 26 & 41 & 48 & 43 & 36 & 30 & 37 \\
\hline $31-40$ & 2 & 19 & 21 & 5 & 4 & 9 & 10 \\
\hline$>40$ & $<1$ & 24 & 18 & 3 & 2 & 15 & 10 \\
\hline$n=100 \%$ & 253 & 233 & 296 & 184 & 359 & 175 & 1500 \\
\hline \multicolumn{8}{|c|}{ Satisfaction with time waited } \\
\hline Very satisfied & 79 & 28 & 41 & 76 & 75 & 58 & 60 \\
\hline Fairly satisfied & 18 & 45 & 42 & 19 & 20 & 28 & 29 \\
\hline Uncertain & 3 & 11 & 10 & 3 & 3 & 5 & 6 \\
\hline Not satisfied & $<1$ & 15 & 8 & 2 & 2 & 9 & 5 \\
\hline$n=100 \%$ & 253 & 233 & 296 & 222 & 359 & 175 & 1538 \\
\hline
\end{tabular}

Table 5. Percentage of users 'very satisfied' with different aspects of the commuter walk-in centres.

\begin{tabular}{|c|c|c|c|c|c|c|c|}
\hline & \multicolumn{3}{|c|}{ In London, \% } & \multicolumn{3}{|c|}{ Out of London, \% } & \multirow[b]{2}{*}{ Total, \% } \\
\hline & A & B & $\mathrm{C}$ & D & $\mathrm{E}$ & $\mathrm{F}$ & \\
\hline Receptionist attitude & 68 & 61 & 59 & 83 & 81 & 72 & 71 \\
\hline Time waited & 79 & 28 & 41 & 76 & 75 & 58 & 60 \\
\hline Nurse/doctor attitude & 87 & 68 & 73 & 92 & 75 & 80 & 78 \\
\hline Explanation given & 80 & 59 & 68 & 80 & 66 & 73 & 70 \\
\hline Treatment or advice & 74 & 53 & 67 & 74 & 64 & 73 & 67 \\
\hline Overall satisfaction & 78 & 51 & 62 & 79 & 72 & 72 & 69 \\
\hline$n=100 \%$ & 259 & 250 & 312 & 205 & 370 & 191 & 1587 \\
\hline
\end{tabular}

receptionist staff did not give surveys to patients they considered were too ill or did not speak English. The response rate was lower than intended and this may have introduced non-response bias. A particular concern is that users who were in a hurry did not complete the questionnaire.

\section{Comparison with existing literature}

The percentage of patients who were very satisfied with this service was lower than for general walk-in centres: ${ }^{1} 69 \%$ versus $80 \%$. A key characteristic of this service was access to a doctor. Although $47 \%$ of users overall saw a doctor, one centre operated more like a general walk-in centre, where $87 \%$ of users normally consulted a nurse. ${ }^{1}$ Similar proportions of users intended to visit a GP compared with general walk-in centres (25\% versus $32 \%$ respectively), ${ }^{1}$ or to attend an emergency department (6\% versus $7 \%){ }^{1}$

\section{Implications for clinical practice}

The walk-in centres made access to care easier for some patients. Patient satisfaction levels were high enough to maintain future use. Waiting time was a key issue, and any increases could affect user satisfaction in the future.

\section{Funding body}

This work was undertaken by the Medical Care Research Unit, which is supported by the Department of Health (017/0045). The views expressed here are those of the authors and not necessarily those of the Department of Health

\section{Ethics approval}

Ethics approval was given by Brighton East LREC (07/Q1907/22)

\section{Competing interests}

The authors have stated that there are none

\section{Acknowledgements}

We would like to thank Martina Santarelli for her assistance in setting up the study.

\section{Discuss this article}

Contribute and read comments about this article on the Discussion Forum: http://www.rcgp.org.uk/bjgp-discuss

\section{REFERENCES}

1. Salisbury C, Manku-Scott T, Moore L, et al. Questionnaire survey of users of NHS walk-in centres: observational study. $\mathrm{Br} J \mathrm{Gen}$ Pract 2002; 52(480): 554-560.

2. O'Cathain A, Coster J, Salisbury C, et al. Do walk-in centres for commuters work? A mixed methods evaluation. Br J Gen Pract 2009; 59: 10.3399/bjgp09X473150. 